Modern Communication Systems 


\section{Other Titles in Electrical and Electronic Engineering}

G. B. Clayton: EXPERIMENTS WITH OPERATIONAL AMPLIFIERS

G. B. Clayton: DATA CONVERTERS

G. B. Clayton: linear INTEGRATEd CirCUit Applications

J. C. Cluley: electronic equipment Reliability, Second Edition

$\boldsymbol{A}$. $\boldsymbol{R}$. Daniels: introduction to electrical machines

C. W. Davidson: transmission LINES for COMmUnications

$W$. Gosling: A FIRST COURSE IN APPLIED ELECTRONICS

B. $A$. Gregory: an introduction to electrical instrumentation and measurement SYSTEMS, Second Edition

Paul A. Lynn: an Introduction to the analysis and Processing of Signals

A. G. Martin and F. W. Stephenson: Linear microelectronic SyStems

R. G. Meadows: ELECTRICAL COMMUNICATIONS THEORY, WORKED EXAMPLES AND PROBLEMS

J. E. Parton and S. J. T. Owen: applied electromagnetics

A. Potton: an introduction to digital logic

J. T. Wallmark and L. G. Carlstedt: FIELD-EFFECT TRANSISTORS IN INTEGRATED CIRCUITS

G. Williams: AN INTRODUCTION TO ELECTRICAL CIRCUIT THEORY 


\title{
Modern Communication Systems
}

\author{
R. F. W. Coates
}

Lecturer in Electronics

University of Wales

Second edition 
@ R. R. W. Coates 1975,1982

All rights reserved. No part of this publication may be reproduced or transmitted, in any form or by any means, without permission

First edition 1975

Reprinted 1978, 1981

Second edition 1983

Published by

THE MACMILLAN PRESS LTD

London and Basingstoke

Companies and representatives throughout the world

ISBN 978-0-333-35832-0 ISBN 978-1-349-86052-4 (eBook)

DOI 10.1007/978-1-349-86052-4

The paperback edition of this book is sold subject to the condition that it shall not, by way of trade or otherwise, be lent, re-sold, hired out, or otherwise circulated without the publisher's prior consent in any form of binding or cover other than that in which it is published and without a similar condition including this condition being imposed on the subsequent purchaser. 


\section{Contents}

1 The Analysis and Synthesis of Waveforms 1

1.1 The Sinusoid 1

1.2 Operations with Sinusoids 6

1.3 The Periodic Waveform 7

1.4 Orthogonality 11

1.5 Fourier Series Analysis in Terms of Sinusoids 12

1.6 Fourier Analysis of a Rectangular-pulse Train 13

1.7 Fourier Series Analysis in Terms of Cisoids 15

1.8 Properties of Generalised Fourier Series 15

1.9 The Analysis of Aperiodic Waveforms 17

1.10 The Fourier Transform 17

1.11 Properties of Fourier Transforms 20

1.12 The Application of Fourier Transforms 21

1.13 The Delta Function 24

1.14 The Use of the Fourier Transform in Spectral Analysis 26

1.15 The Use of the Fourier Transform in Determining the Line Spectrum of Periodic Functions 26

1.16 The Use of the Fourier Transform in Describing Linear Filtering

1.17 Ideal Filters
1.18 Calculating the Transfer Function of Practical Electronic Filters $\quad 37$

1.19 Energy-density and Power-density Spectra 40

1.20 Energy Spectral Density of Finite-energy Pulses 41

1.21 Energy Spectral Density of the Delta Function 44

1.22 Power Spectral Density of Finite-power Periodic Functions 44

1.23 Power Spectral Density of Finite-power Aperiodic Functions 
1.24 The Cross- and Autocorrelation Functions and the Correlation Coefficient

1.25 The Use of The Autocorrelation Function in Determining Power Spectra

1.26 The Use of the Autocorrelation Function in Determining Energy Spectra

1.27 Some examples of the Calculation and Use of the Autocorrelation Function

1.28 Fourier Transforms: A Credibility Gap?

Problems

2 The Information Source and Communication Channel 60

2.1 The Primary Information Source 60

2.2 The General Properties of Communication Channels 64

2.3 Electromagnetic Propagation Through the Atmosphere 66

2.4 The Transmission Line as a Communication Medium 69

2.5 The Physics of Line Operation 71

2.6 The Terminated Line 73

2.7 The 'Lossless' Line 75

2.8 Multicore Telephone Cable 76

2.9 The Distortionless Line 77

2.10 Coaxial Cable 78

2.11 Repeaters and Equalisers $\quad 79$

2.12 Optical Communications $\quad 80$

2.13 Modulators 84

2.14 Sinusoidal Modulation $\quad 86$

$\begin{array}{ll}\text { Problems } & 87\end{array}$

3 Envelope Modulation $\quad 90$

3.1 Product Modulation 91

3.2 The Detection of Product-modulated Waves 94

3.3 Conventional Amplitude Modulation 95

3.4 Band Occupancy of Conventional AM 97

3.5 Transmission Efficiency in Envelope Modulation 98

3.6 Conventional AM and the Sinusoidal Test Signal 100

3.7 System Implementation: Modulators 102

3.8 System Implementation: Demodulators 113

3.9 The Effect of Noise in the Detection of Envelopemodulated Waves 115

3.10 Signal-to-noise Ratio at the Output of the Product Demodulator

3.11 Signal-to-noise Ratio at the Output of the Envelope Detector

Problems

4.1 The General Angle-modulated Sinusoid 124

4.2 The Problem of Spectral Analysis 128 
$\begin{array}{ll}\text { 4.3 A Quasi-linear Spectral Analysis } & 129\end{array}$

4.4 A Quasi-static Spectral Analysis 132

4.5 Band Occupancy of Angle-modulated Waves 135

4.6 The Sinusoidal Test Signal 137

4.7 System Implementation: Modulators 142

4.8 System Implementation: Demodulators 147

4.9 Noise Analysis: Frequency Modulation 151

4.10 Noise Analysis: Phase and Pre-emphasised Frequency Modulation

4.11 The Threshold and its Importance in System Design 162 Problems

5 Composite Modulation

5.1 Quadrature Amplitude Modulation 168

5.2 Single-sideband Modulation 169

5.3 The Detection of Single-sideband Modulation 175

5.4 Asymmetric- and Vestigial-sideband Modulation 176

5.5 Independent-sideband Modulation 177

5.6 Noise in Single-sideband Detection 177

5.7 Baseband-equivalent Modulation Processes 178

$\begin{array}{ll}5.8 \text { Applications of Composite Modulation } & 179\end{array}$

Problems

6 Sampling and Pulse Code Modulation 182

6.1 The Sampling Principle 184

6.2 The Sampler 186

6.3 The Sample and Hold Operation 187

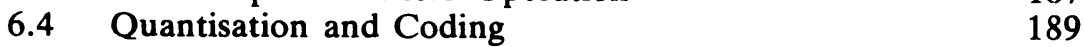

6.5 Quantisation Noise 190

6.6 Coding for Technological Convenience 191

6.7 Pulse Code Modulation 193

6.8 Digital-to-analogue Conversion 197

6.9 Feedback Analogue-to-digital Conversion 203

6.10 Generating a Symmetrical Binary Code 207

6.11 Generating a Symmetrical Code Corresponding to a Nonuniform Quantiser Law 208

6.12 Differential PCM and Predictive Encoding 214

6.13 Delta Modulation Systems 220

6.14 The CODEC 233

Problems 243

7 Coding for Error Protection and Security 245

7.1 The Principles of Error Protection 246

$\begin{array}{lll}7.2 & \text { Modulo-2 Arithmetic } & 248\end{array}$

7.3 Elementary Block Coding and Decoding 251

7.4 Cyclic Block Codes 258 
7.5 Decoding Cyclic Codes 262

$\begin{array}{lll}7.6 & \text { Polynomial Codes } & 271\end{array}$

7.7 Maximal Length Shift Register Sequences 274

$\begin{array}{ll}7.8 & \text { Convolution or Recurrent Codes } \\ 7 & 277\end{array}$

$\begin{array}{lll}7.9 & \text { Encryption Systems } & 285\end{array}$

7.10 Protection of Voice Communication 290

7.11 Spread Spectrum Communication Systems 291

Problems $\quad 294$

8 The Transmission of Digital Signals 296

8.1 Band Occupancy of Random Digital Data 297

8.2 Code Conversion to Aid Transmission 300

8.3 Pre-transmission and Pre-detection Filtering 303

8.4 Partial Response Signalling 307

$\begin{array}{lll}8.5 & \text { Eye Patterns } & 309\end{array}$

$\begin{array}{ll}8.6 \text { Keying Techniques } & 310\end{array}$

$\begin{array}{ll}8.7 & \text { Multilevel Keying Systems } \\ 8.820\end{array}$

8.8 Bandwidth Economical Keying Systems 323

8.9 Line Equalisation Techniques 330

8.10 Transmission Error Probability 333

8.11 Block Error Probability 341

8.12 Data Channel Throughput 342

Problems $\quad 344$

9 The Integrated Services Digital Network 347

9.1 A Perspective on Telephony 348

9.2 Frequency Division Multiplex Telephony 353

$\begin{array}{ll}\text { 9.3 Pulse Code Modulation Telephony } & 355\end{array}$

9.4 Telephone Circuit Switching 356

9.5 Telephony Signalling Procedures 364

9.6 Stored Program Control 365

$\begin{array}{lll}9.7 & \text { SPC Software } & 369\end{array}$

$\begin{array}{lll}9.8 & \text { Packet Switching } & 371\end{array}$

Appendix I: A Table of Useful Fourier Transform Pairs 377

Appendix II: Mathematical Functions 383

Appendix III: Noise Sources and Their Effect Within the Communication System 385

$\begin{array}{ll}\text { Bibliography } & 389\end{array}$

$\begin{array}{ll}\text { Index } & 393\end{array}$ 


\section{Preface to the First Edition}

This text is intended to cover a two-year course on communication system engineering at B.Sc. level. The subject material is based upon courses which I have taught at both the University of Wales and the University of London.

Chapter 1 concentrates upon the use of Fourier methods in the analysis and processing of waveforms. It provides the mathematical groundwork upon which the rest of the book is based.

The communication channel and the problems it presents to the system designer are studied in chapter 2.

Chapters 3, 4 and 5 are concerned with the various methods of modulating a sinusoidal carrier. Much of the material presented in these chapters is standard and has been well-documented in other undergraduate texts. None the less, I have attempted to introduce modern techniques wherever possible. In particular, I have tended to stress such system implementations as lead naturally to integrated-circuit fabrications. For example, in chapter 4 , the principle of frequency discrimination and the desirable features required of a practical discriminator are considered, leading to a description of the Travis discriminator. Instead of following the usual policy and covering the Foster-Seeley and ratio detectors in great detail, the available space has been devoted to introducing that quite-different frequency detector: the phase-locked loop. This system module is now available as an integrated circuit. It is cheap, requires little trimming and involves no transformers. It must, surely, become the major means of attaining frequency detection, even in domestic receivers, in the near future.

The titles of chapters 3,4 and 5 are 'Envelope Modulation', 'Angle Modulation' and 'Composite Modulation', respectively. Single-sideband systems, being a combined envelope and phase modulation, therefore appear in chapter 5 . It is common policy, in most texts, to include them with envelope (amplitude) modulation. I hope that the slightly unusual classification employed here will help the student to appreciate the nature of single-sideband waveforms more clearly.

Digital techniques are discussed in chapters 6,7 and 8 in greater detail than has been customary in most undergraduate texts. Notwithstanding 
the small amount of time commonly devoted to these topics, they represent the major growth area in communication system installation at the present time; in particular, digital-data links are becoming an area of great importance. In this respect, I hope that the discussions of both digital coding and data transmission reflect modern practice with reasonable accuracy and provide an indication of trends in the immediate future.

In a text of this nature, space is at a premium and, if the cost of the final work is not to become excessive, some omissions are inevitable. It is with regret, for example, that I have not been able to include descriptions of differential pulse code modulation and delta modulation. The latter system, particularly, is of increasing interest to many engineers. However, it has not yet found extensive practical application in communication systems.

Let me reiterate the function of this book before defending the omission of one major topic. The objective is to teach undergraduates about communication systems. Communications is a vast field; one that is capitalintensive and makes heavy demands on available skilled manpower. The book, then, must attempt to present the principles upon which modern communication system design is based. It must also, perhaps to a lesser extent, present an outline of current practice. A conflict in aims, therefore, tends to arise when we come to consider the suitability of including such subjects as statistical decision theory and information theory. Practice makes it evident that profitable systems are not, in the main, designed as a consequence of the application of the principles which derive from these disciplines.

Thus the techniques used in the design of data modems do not, in practice, derive from decision-making strategies suggested by statistical decision theory. Nor does the use of frequency modulation result from the application of the methods of information theory. It is true that information theory, and in particular Shannon's well-known theorem

information transfer $=$ channel bandwidth $\times$ transmission time

$$
\times \log (1+\text { signal/noise ratio })
$$

throws light on the efficacy of the tradeoff between bandwidth and signalto-noise ratio evidenced by frequency-modulation systems. It is also arguable that Shannon's theorem provides us with upper bounds beyond which we cannot expect to improve the performance of communication systems; perhaps it does. Unfortunately, it is rarely the case that the postulates used in deriving the theorem are all encountered in a real system. Also, most real systems exhibit a performance level well below the Shannon bound. Finally, information theory suggests no way of designing systems so that the bound is approached. Hence its omission in favour of topics of greater practical importance to the young engineer about to seek employment.

Let me conclude by extending my appreciation to the people who have helped me during the preparation of this book, I would like to thank my colleagues, David Armitage, David Everett and Robert Newton for many helpful discussions and for reading and criticising the manuscript with such diligence. For his assistance in preparing and executing the diagrams, 
particularly some of the more difficult, I would like to thank my father, Stafford Coates, Principal Lecturer, Southampton College of Technology. Finally, thanks are due to my mother, Mollie, and my wife, Gillian, for their support and encouragement during the writing of this book.

October 1974

RODNEy Coates

\section{Preface to the Second Edition}

In the short period of seven years since the publication of the first edition of this book, many significant and, in some respects unforseeable, changes in communication system technology have emerged. In particular the 'microprocessor revolution', the rapid escalation in complexity of computing microcircuitry, has provided the communication engineer with powerful, yet flexible and easily implemented processing capabilities. Taken in conjunction with fibre optic and satellite technology and the need to sustain ever-expanding computer data-bases and communication facilities, such capabilities pave the way for a second revolution: the 'information revolution' predicted for the closing decade of this century.

Respecting the pace and nature of communication system developments, I have included a new chapter: 'The Integrated Services Digital Network'. This will I hope provide an orientation for the engineer in a field of some complexitynamely, the structure and organisation of the future international telephony and data-transfer network-which, in social terms, must profoundly affect us all.

In chapters 6, 7 and $8 \mathrm{I}$ have added new material emphasising the importance of digital techniques in the communications industry. Indeed, much of the material included in chapter 6 (in particular, that concerning differential pulse code and delta modulation) had to be deliberately omitted from the first edition, being at that time insufficiently important to warrant inclusion. Now, both techniques are essential material for the understanding of the integrated circuit 'CODEC'. This device (described in detail in chapter 6) will, it has been predicted, account for a major proportion of the revenue of the integrated circuit fabrication industry by the end of the present decade.

Changing social attitudes and the volume and sensitivity of commercial information transfer have persuaded me to include in chapter 7 discussions of the use of coding techniques in speech and data communication to achieve security and privacy. In chapter 8 , consideration is given to advanced data keying systems and modem techniques. Finally, new material providing a resumé of the significance of fibre optic communications in modern communication networks is to be found in chapter 2. 
Despite the inclusion of considerable new material, much has, inevitably, been left unsaid. It is my hope, however, that within the following pages, the engineer will find a helpful overview of this vast, expanding and vitally important field of human endeavour. Finally, I am indebted to Larry Lind for reading and correcting the manuscript and for his many useful suggestions throughout the production of this new edition.

May, 1982

RODNEY COATES 